\title{
Microwave enhanced stabilization of heavy metal sludge
}

\author{
Ching-Hong Hsieh ${ }^{\text {a }}$, Shang-Lien Lo ${ }^{\mathrm{a}, *}$, Pei-Te Chiueh ${ }^{\mathrm{b}}$, Wen-Hui Kuan ${ }^{\mathrm{c}}$, Ching-Lung Chen ${ }^{\mathrm{a}}$ \\ ${ }^{a}$ Research Center for Environmental Pollution Prevention and Control Technology, Graduate Institute of Environmental Engineering, \\ National Taiwan University, 71 Chou-Shan Road, Taipei 106, Taiwan, ROC \\ ${ }^{\mathrm{b}}$ Department of Environmental Management, Tung Nan Institute of Technology, Taiwan, ROC \\ ${ }^{\mathrm{c}}$ Department of Environmental and Safety Engineering, Ming-Chi University of Technology, No. 84, Gongjhuan Road, Taishan, Taipei Hsien 243, Taiwan, ROC
}

Received 26 March 2006; received in revised form 7 June 2006; accepted 7 June 2006

Available online 12 June 2006

\begin{abstract}
A microwave process can be utilized to stabilize the copper ions in heavy metal sludge. The effects of microwave processing on stabilization of heavy metal sludge were studied as a function of additive, power, process time, reaction atmosphere, cooling gas, organic substance, and temperature. Copper leach resistance increased with addition of aluminum metal powder, with increased microwave power, increased processing time, and using a gaseous environment of nitrogen for processing and air for cooling $\left[\mathrm{N}_{2} /\right.$ air $]$. The organic in the sludge affected stabilization, whether or not the organic smoldered. During heating in conventional ovens, exothermic oxidation of the organic resulted in sludge temperatures of about $500{ }^{\circ} \mathrm{C}$ for oven control temperatures of $200-500{ }^{\circ} \mathrm{C}$. After microwave heating dried the sludge, the sludge temperature rose to $500{ }^{\circ} \mathrm{C}$. The reaction between copper ions and metal aluminum in the dried sludge should be regarded as a solid phase reaction. Adding aluminum metal powder and reaction temperature were the key parameters in stabilizing copper in the heavy metal sludge, whether heated by microwave radiation or conventional oven. The mass balance indicates insignificant volatization of the copper during heating.
\end{abstract}

(C) 2006 Elsevier B.V. All rights reserved.

Keywords: Microwave; Heavy metal sludge; Stabilization

\section{Introduction}

Heavy metal sludge produced from the sequence of flocculation, $\mathrm{pH}$ adjustment, and alkaline precipitation in printed circuit board plants are often regarded as hazardous material. In addition to metal ions and insoluble metal hydroxide, the heavy metal sludge contained several salts $\left(\mathrm{CaSO}_{4}, \mathrm{CaCO}_{3}, \mathrm{NaCl}\right.$, and $\mathrm{NaHCO}_{3}$ ) and a polymer that is used as a chelating agent [1]. In Taiwan, the copper is recovered from waste metal sludge by sulfuric acid extraction and copper compound crystallization. TCLP leaching of the residual sludge still results in leachate copper concentrations above the legal limit for land disposal $(<15 \mathrm{mg} / \mathrm{L})$. Therefore, further treatment of the residual sludge is required before landfill disposal.

Compared with other conventional thermal treatment technologies, the microwave technique with the characteristics of polar oscillation and effect of dielectric losses offers the advantage of selective, uniform, and rapid heating. For solid phase

\footnotetext{
* Corresponding author. Tel.: +886 223625373; fax: +886 223928830.

E-mail address: sllo@ntu.edu.tw (S.-L. Lo).
}

samples with heterogeneous composition, the phenomena of superheating and hot spot were encountered [2]. Furthermore, electromagnetic microwave has also been widely used in the treatment of environmental materials, such as heating and pyrolysis [3,4], assisted extraction and digestion [5-8], organic and inorganic synthesis [9-11], and sample preparation [12,13]. Moreover, growing interests in stabilization and immobilization of metal ions in soil and sludge through microwave radiation have also been reported [14-18]. Results indicated that microwave radiation inhibits leaching of metal ions from soil or sludge and that it makes these solid wastes acceptable for disposal or recycle.

In this study, the stabilization of heavy metal sludge enhanced by microwave radiation was investigated. The objects of this study were to: (1) determine the proper procedure for stabilization of heavy metal sludge by microwave energy, (2) discuss the effects of additives, reaction atmosphere, cooling gas, organic substances and temperature, (3) compare the difference between conventional oven and microwave radiation on sludge stabilization, and (4) conjecture the stabilizing mechanism of heavy metal sludge. 
Table 1

Operating conditions of different treatment

\begin{tabular}{|c|c|c|c|c|}
\hline Experiment & Additive & Power (W) & $\begin{array}{l}\text { Process time } \\
(\min )\end{array}$ & $\begin{array}{l}\text { Atmosphere and } \\
\text { cooling gas }\end{array}$ \\
\hline Effect of additive & $\begin{array}{l}\mathrm{Al} \text { powder }(0-3.09 \mathrm{~g}), \alpha-\mathrm{Al}_{2} \mathrm{O}_{3} \\
(0-2 \mathrm{~g}), \gamma-\mathrm{Al}_{2} \mathrm{O}_{3}(0-2 \mathrm{~g})\end{array}$ & 600 & 12 & Air \\
\hline Effect of microwave power and process time & $\mathrm{Al}$ powder $(0.39$ and $0.58 \mathrm{~g})$ & $400,600,800$ & $0-25$ & Air \\
\hline Effect of atmosphere and cooling gas & $\mathrm{Al}$ powder $(0,0.39$ and $0.58 \mathrm{~g})$ & 600 & $0-15$ & Air or $\mathrm{N}_{2}$ \\
\hline Effect of organics (Stage I) & No additive & 600 & 12 & Air \\
\hline Effect of organics (Stage II) & $\mathrm{Al}$ powder $(0.58 \mathrm{~g})$ & 600 & $0-15$ & Air \\
\hline
\end{tabular}

\section{Materials and methods}

\subsection{Sample preparation and analysis}

Raw heavy metal sludge from a Heavy Metal Sludge Treatment Plant in Taiwan had been treated by an acid extraction process. However, in terms of toxic characteristics leaching procedure (TCLP, R.1311, US EPA), copper ion concentrations of the raw sludge at moisture content $0 \%(132 \mathrm{mg} / \mathrm{L})$ still do not meet the criteria of waste disposal in Taiwan $(15 \mathrm{mg} / \mathrm{L})$ and therefore a stabilizing treatment of heavy metal sludge is needed before disposal or reuse.

The pretreatment steps of the raw heavy metal sludge were as follows: (1) dry in an oven at $105^{\circ} \mathrm{C}$ until the mass maintains a constant value within $\pm 1 \%$ (about $12 \mathrm{~h}$ ), (2) crush the dried sludge with a grinder, (3) sieve to a particle diameter between 100 and 400 mesh $(0.15-0.063 \mathrm{~mm})$, and (4) store the dried, crushed, sieved sludge in a $20 \mathrm{~L}$ bucket with a plastic cover. Worth note that the term "RS" used in this study means raw sludge after pretreatment.

The metal composition of the RS was determined by a modified microwave digestion method reported in previous studies $[6,19]$. Samples of raw heavy metal sludge $(0.1 \mathrm{~g})$ were mixed with a $\mathrm{HNO}_{3}-\mathrm{HCl}-\mathrm{HF}$ solution $(3 \mathrm{~mL})$. These acid slurries were processed using the following two-stage microwave program: (1) $650 \mathrm{~W}$ for $10 \mathrm{~min}$ (final temperature $160^{\circ} \mathrm{C}$ ) and (2) $800 \mathrm{~W}$ for $15 \mathrm{~min}$ (final temperature $200^{\circ} \mathrm{C}$ ). After the microwaveassisted digestion, the mixtures were cooled to room temperature, filtered, and the filtrate volume adjusted to $50 \mathrm{~mL}$ before analysis. The same microwave digestion method was also performed on the stabilized sludge, $\mathrm{SS}_{\mathrm{L}}$, after stabilization with $0.58 / 40(\mathrm{~g} / \mathrm{g})$ aluminum powder/sludge at $600 \mathrm{~W}$ microwave radiation for $12 \mathrm{~min}$.

In the experiments, $40 \mathrm{~g}$ of $\mathrm{RS}$ was put in $\mathrm{SiO}_{2}$ ceramic crucible (11 cm diameter) and the sludge moisture content adjusted to $50 \mathrm{wt} . \%$ with deionized water. An industrial microwave oven was used in this study with a microwave frequency of $2.45 \mathrm{GHz}$ and variable power up to $1600 \mathrm{~W}$. Treated samples were leached using TCLP and the leaching concentrations of $\mathrm{Cu}, \mathrm{Fe}$, and $\mathrm{Al}$ were analyzed by inductively coupled plasma-atomic emission spectrometry (ICP-AES).

\subsection{Different orders of processing}

The following four orders of processing were tested: (1) microwave radiation of $600 \mathrm{~W}$ and process time of $12 \mathrm{~min}$ with- out adding any aluminum powder, (2) adding aluminum powder without microwave radiation, (3) with microwave radiation of $600 \mathrm{~W}$ and process time of $12 \mathrm{~min}$ then with the addition of aluminum powder, and (4) aluminum powder of $0.58 \mathrm{~g}$ was added with simultaneous microwave radiation.

\subsection{Additives}

Three aluminum series additives, aluminum powder, $\alpha$ $\mathrm{Al}_{2} \mathrm{O}_{3}$, and $\gamma-\mathrm{Al}_{2} \mathrm{O}_{3}$, with different microwave adsorption properties were tested in the following range of masses added per $40 \mathrm{~g}$ of RS: (1) 0-3.09g of aluminum metal powder, (2) $0-2 \mathrm{~g}$ of $\alpha-\mathrm{Al}_{2} \mathrm{O}_{3}$, and (3) $0-2 \mathrm{~g}$ of $\gamma-\mathrm{Al}_{2} \mathrm{O}_{3}$. The operating conditions were microwave power of $600 \mathrm{~W}$, process time of $12 \mathrm{~min}$, and reaction atmosphere/cooling gas of air/air (see Table 1).

\subsection{Microwave power and process time}

In the microwave heating experiments, the higher the microwave power, the shorter the process time needed. Therefore, the effect of microwave power and process time were studied with the addition of aluminum powder and the operating parameters that are listed in Table 1.

\subsection{Effect of reaction atmosphere and cooling gas}

Two gases were used as the reaction atmosphere and cooling gas: air and nitrogen. The test procedure for establishing the ambient gas during the test follows: (1) put the sample in the microwave oven, (2) evacuate the oven with a vacuum pump, (3) fill the oven with the reaction atmosphere (air or nitrogen) to a pressure of nearly $76 \mathrm{cmHg}$, (4) perform the stabilizing experiment, and (5) vent the oven and blow the cooling gas (air or nitrogen) through the oven for $15 \mathrm{~min}$.

\subsection{Organics}

A polymer used during heavy metal wastewater treatment made the organic content of the heavy metal sludge significant, almost $25 \%(\mathrm{w} / \mathrm{w})$. A two-stage experiment was designed to better understand the influence of the organic content on stabilization. This experiment consisted of the following steps: (1) microwave RS at $600 \mathrm{~W}$ for $12 \mathrm{~min}$ to break down or decompose the organics (end of Stage I), (2) take $40 \mathrm{~g}$ of the sludge from Stage I and adjust its moisture content to $50 \%$ (w/w), (3) add 
Table 2

Chemical composition of RS and $\mathrm{SS}_{\mathrm{L}}$

\begin{tabular}{lll}
\hline Element & RS $(\mathrm{mg} / \mathrm{g})$ & $\mathrm{SS}_{\mathrm{L}}(\mathrm{mg} / \mathrm{g})$ \\
\hline $\mathrm{Ag}$ & N.D. & N.D. \\
$\mathrm{Al}$ & 3.77 & 4.80 \\
$\mathrm{Ba}$ & 2.06 & N.D. \\
$\mathrm{Ca}$ & 66.91 & 66.60 \\
$\mathrm{Cd}$ & N.D. & N.D. \\
$\mathrm{Co}$ & N.D. & N.D. \\
$\mathrm{Cr}$ & N.D. & N.D. \\
$\mathrm{Cu}$ & 11.58 & 11.30 \\
$\mathrm{Fe}$ & 13.68 & 13.09 \\
$\mathrm{Ga}$ & N.D. & N.D. \\
$\mathrm{K}$ & 6.01 & 5.27 \\
$\mathrm{Mg}$ & 1.68 & 1.69 \\
$\mathrm{Mn}$ & 0.05 & N.D. \\
$\mathrm{Na}$ & 14.69 & 11.60 \\
$\mathrm{Ni}$ & N.D. & N.D. \\
$\mathrm{Pb}$ & 0.15 & N.D. \\
$\mathrm{Si}$ & 85.40 & 85.00 \\
$\mathrm{Zn}$ & 0.52 & 0.56 \\
& & \\
$\mathrm{ND}$ & &
\end{tabular}

N.D., not detected.

$0.58 \mathrm{~g}$ aluminum metal powder, and (4) microwave at $600 \mathrm{~W}$ for times ranging from 0 to $15 \mathrm{~min}$ (end of Stage II, see Table 1).

\subsection{Temperature}

Temperature is an important factor in thermal treatment of solid waste. A conventional oven gave a controlled temperature environment in which to place sludge for studying the effect of temperature. The difference between conventional heating and microwave heating is discussed. Each test used $40 \mathrm{~g}$ of RS with the moisture content adjusted to $50 \%$ (w/w). Some had $0.39 \mathrm{~g}$ of aluminum metal powder added and some did not. The samples were placed in a conventional oven at temperatures of 200, 300, 400 , or $500^{\circ} \mathrm{C}$, and the sludge temperature recorded with time. Another oven experiment was also performed with RS without additive at stationary oven temperatures of 200, 300, 400, 500, 700 , or $800^{\circ} \mathrm{C}$ for a heating time of $6 \mathrm{~h}$.

\section{Results and discussion}

\subsection{Chemical composition of RS and stabilized sludge}

Table 2 lists the extractable elemental composition measured in samples of the RS and the stabilized heavy metal sludge, $\mathrm{SS}_{\mathrm{L}}$.
The major elements in the sludge were $\mathrm{Si}, \mathrm{Ca}, \mathrm{Fe}, \mathrm{Cu}$, and $\mathrm{Al}$ in decreasing sequence. The large amounts of $\mathrm{Ca}, \mathrm{Fe}$, and $\mathrm{Al}$ in the RS are attributed to the usage of lime, ferrous sulfate, and poly aluminum chloride, respectively, in wastewater treatment, while the $\mathrm{Cu}$ and $\mathrm{Si}$ came from the printed circuit board treatment. The copper concentrations in the RS and $\mathrm{SS}_{\mathrm{L}}$ were 11.58 and $11.3 \mathrm{mg} / \mathrm{g}$, respectively. The concentration difference is only $2.4 \pm 0.2 \%$ between the $\mathrm{RS}$ and $\mathrm{SS}_{\mathrm{L}}$, meaning copper volatization was negligible during the thermal treatment. The decrease of copper leaching concentration in stabilizing experiments may be attributed to the conversion of copper species. The instrument detection limit (IDL) of the liquid extract was of $0.1 \mathrm{mg} / \mathrm{L}$, which translates into a detection limit for the sludge of $0.05 \mathrm{mg} / \mathrm{g}$. Thus, N.D., or "not detected", in Table 2 means $<0.05 \mathrm{mg} / \mathrm{g}$. All the values of metal concentration, $\mathrm{mg} / \mathrm{g}$, listed in Table 2 were corrected to the equivalent RS basis.

\subsection{Choice of stabilizing processes}

For Case I in Table 3, the RS with moisture adjusted to 50\% (w/w) was in an aerobic condition and subjected to microwave radiation with no aluminum metal powder, resulting in a TCLP copper leaching concentration much higher than before treatment. The sludge dried after microwaving $12 \mathrm{~min}$ and the temperature rose to $500{ }^{\circ} \mathrm{C}$, causing the organics (a polymer chelating agent) in the sludge to smolder. The polymer oxidized or decomposed, releasing the copper hydroxide trapped in the polymer to subsequently be leached during TCLP testing.

In Cases II and III, the TCLP copper leaching concentrations still exceeded the criterion for waste disposal in Taiwan $(15 \mathrm{mg} / \mathrm{L})$. Only Case IV decreased the TCLP copper leaching concentration below this regulatory limit. Therefore, the experimental process of Case IV was adopted as the stabilization process of choice.

\subsection{Effect of additives, microwave power and process time}

Fig. 1 illustrates the effect of different aluminum additives and their dosage by the following observations: (1) the TCLP copper concentrations dropped dramatically upon the addition of the aluminum additives up to an additive/RS ratio of about $0.39 / 40(\mathrm{~g} / \mathrm{g})$, but remained relatively flat with further additions. (2) There was no obvious difference in microwave stabilizing tendency between $\gamma-\mathrm{Al}_{2} \mathrm{O}_{3}$ with higher microwave absorbance and $\alpha-\mathrm{Al}_{2} \mathrm{O}_{3}$ with lower microwave absorbance. (3) Aluminum

Table 3

The TCLP concentration of metals from different treatments

\begin{tabular}{|c|c|c|c|c|}
\hline \multirow[t]{2}{*}{ Case } & \multirow[t]{2}{*}{ Treatment } & \multicolumn{3}{|c|}{ TCLP concentration $(\mathrm{mg} / \mathrm{L})$} \\
\hline & & $\mathrm{Cu}$ & $\mathrm{Fe}$ & $\mathrm{Al}$ \\
\hline RS & None & $132.0^{\mathrm{a}}$ & N.D. & 17.28 \\
\hline I & Microwave radiation only $(600 \mathrm{~W} \times 12 \mathrm{~min})$ & $445.1^{\mathrm{a}}$ & N.D. & 20.4 \\
\hline II & Al powder only ( $0.58 \mathrm{~g} \mathrm{Al}$ powder/40 g RS) & $55.1^{\mathrm{a}}$ & 22.71 & 92.44 \\
\hline III & 1. Microwave radiation $(600 \mathrm{~W} \times 12 \mathrm{~min}) .2$. Additive $(0.58 \mathrm{~g} \mathrm{Al}$ powder $/ 40 \mathrm{~g} \mathrm{RS})$ & $221.7^{\mathrm{a}}$ & 5.85 & 12.68 \\
\hline IV & Additive $(0.58 \mathrm{~g} \mathrm{Al}$ powder $/ 40 \mathrm{~g} \mathrm{RS})+$ microwave radiation $(600 \mathrm{~W} \times 12 \mathrm{~min})$ & 3.6 & 230.3 & 131 \\
\hline
\end{tabular}

\footnotetext{
a Exceeds the TCLP criterion of $15 \mathrm{mg} / \mathrm{L}$ for Taiwan.
} 


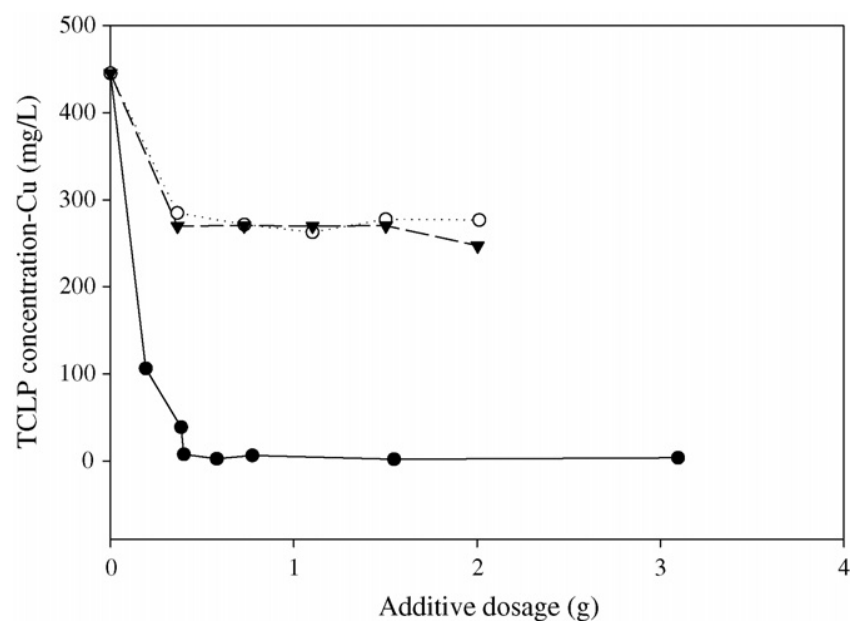

Fig. 1. The effect of additives: $(\bullet)$ aluminum power, $(\bigcirc) \alpha-\mathrm{Al}_{2} \mathrm{O}_{3}$, and $(\boldsymbol{\nabla})$ $\gamma-\mathrm{Al}_{2} \mathrm{O}_{3}$.

powder combined with microwave radiation effectively stabilized the copper in the heavy metal sludge. These results indicate that the lattice arrangement of $\mathrm{Al}$ species is not a factor in the stabilization of heavy metal sludge, but the valence of the $\mathrm{Al}$ species is. Apparently, the aluminum metal powder effectively reduced the copper species in the sludge under microwave heating. Iron powder or iron wire of zero valence efficiently decreased the leaching concentration of metal ions in solid wastes with microwave radiation in prior studies [14-16]. In the preliminary studies of this work, the addition of $\mathrm{Fe}_{2} \mathrm{SO}_{4} \cdot 7 \mathrm{H}_{2} \mathrm{O}$ or $\mathrm{FeCl}_{3}$ did not effectively stabilize the heavy metal sludge. Also, decomposing organic carbon during microwave heating not only did not reduce or stabilize the copper at the temperatures attained, but also released the copper ions chelated in the organic carbon to be more easily leached in subsequent TCLP testing. Apparently, the reducing ability of metal powders is required to stabilize the metals in heavy metal sludge at the levels of microwave power and temperatures used in this study. The role of the silicon, alkaline, and alkali species in this stabilization is uncertain, but likely result in thermodynamically stable metal-alumina-oxide species.

Fig. 2 shows that the leaching concentration of copper ions decreased with the increasing values of microwave power, process time, and aluminum quantity $(0-0.58 \mathrm{~g} \mathrm{Al} / 40 \mathrm{~g} \mathrm{RS}$ ( $\mathrm{g} / \mathrm{g}$ ), no improvement above $0.58 / 40(\mathrm{~g} / \mathrm{g})$ ). The experimental data varied more at higher microwave power. The intermediate microwave power of $600 \mathrm{~W}$ was used in later experiments as a compromise between more efficient stabilization and reproducibility. The reducing ability of aluminum powder may be responsible for the decreasing of copper leachability during the first $3 \mathrm{~min}$ (see Fig. 2). Dissolved $\mathrm{Cu}(\mathrm{OH})_{2}$ may be reduced to $\mathrm{Cu}^{0}$, which was not easily oxidized to $\mathrm{CuO}$ and hydrated back to dissolved $\mathrm{Cu}(\mathrm{OH})_{2}$ during TCLP testing. During the 3-9 min period, the moisture of the heavy metal sludge gradually decreased, reaching $0 \mathrm{wt} . \%$ at the 9 min mark and the temperature of the sludge was below $150{ }^{\circ} \mathrm{C}$. This temperature is too low to destroy the organic chelate and release more copper ions for reduction. Thus, the stabilizing efficiency decreased or did not improve

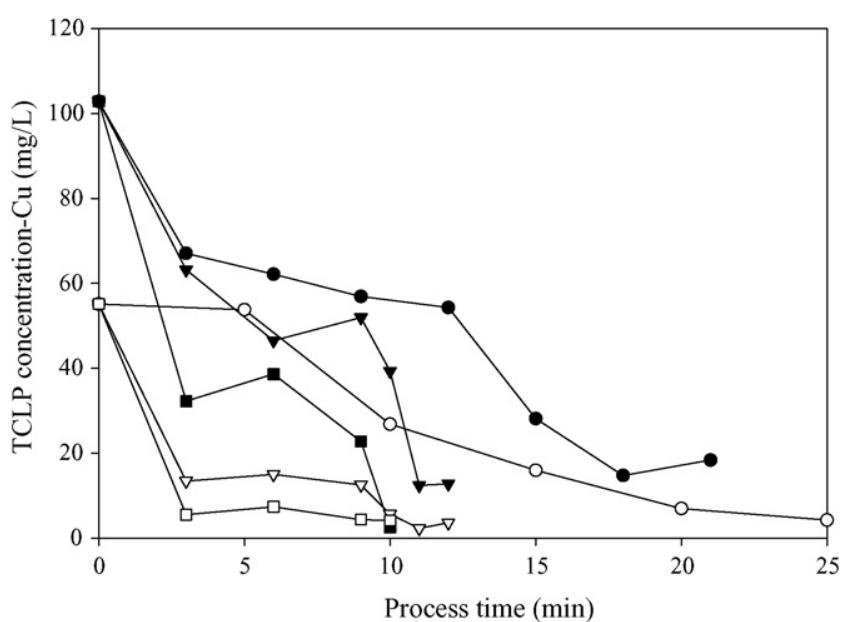

Fig. 2. The effect of microwave power and process time. Addition of $0.39 \mathrm{~g} \mathrm{Al}$ powder with microwave radiation of $(\boldsymbol{\bullet}) 400 \mathrm{~W},(\boldsymbol{\nabla}) 600 \mathrm{~W}$, and (⿴) $800 \mathrm{~W}$. Addition of $0.58 \mathrm{~g} \mathrm{Al}$ powder with microwave radiation of $(\bigcirc) 400 \mathrm{~W},(\nabla)$ $600 \mathrm{~W}$, and $(\square) 800 \mathrm{~W}$.

during this time period. Past 9 min, with the moisture vaporized, the temperature of the heavy metal sludge rose steeply up to $450-500{ }^{\circ} \mathrm{C}$ and the organic contents smoldered and were destroyed. The weight loss from organic destruction (about $25 \%$ loss) was not included in the calculation of weight loss for the samples. In the phase after $9 \mathrm{~min}$, the stabilizing efficiency increased with time, because of the higher temperature of the heavy metal sludge from microwave radiation in the absence of water. The reaction between copper ions and additive is a solid phase reaction at this point. In a solid phase reaction, the reactants cannot migrate freely and the theories of Brownian motion do not apply. Therefore, the reaction mechanism at this stage cannot be interpreted entirely by the theories of aqueous chemistry.

\subsection{Effect of reaction atmosphere and cooling gas}

The effect of reaction atmosphere and cooling gas is essential for understanding a microwave system. Fig. 3 shows no stabilization occurred without the additive, whether the reaction atmosphere and cooling gas were air or nitrogen. The organics in the sludge was completely oxidized for air/air (reaction gas/cooling gas) within 9 min, making the copper ions more leachable in the TCLP test. The $\mathrm{N}_{2} / \mathrm{N}_{2}$ combination prevented this oxidation and kept the rising temperature moderate (under $150^{\circ} \mathrm{C}$ ). Therefore, it was supposed that under microwave radiation and an inert reaction atmosphere, the organic substance would consume little of the aluminum powder in later stabilizing experiments. Fig. 4 illustrates that the best combination was a $\mathrm{N}_{2}$ reaction atmosphere coupled with cooling air, shortening the process time for stabilization of the heavy metal sludge. The microwave radiation may increase the energy and reactivity of the aluminum powder, but the inert atmosphere decreases the oxidation and destruction of the organic, implying that the activated $\mathrm{Al}$ powder was not consumed by the organic. In addition, the cooling air may improve the reaction between aluminum powder and copper ions, but the lower temperature prevented 


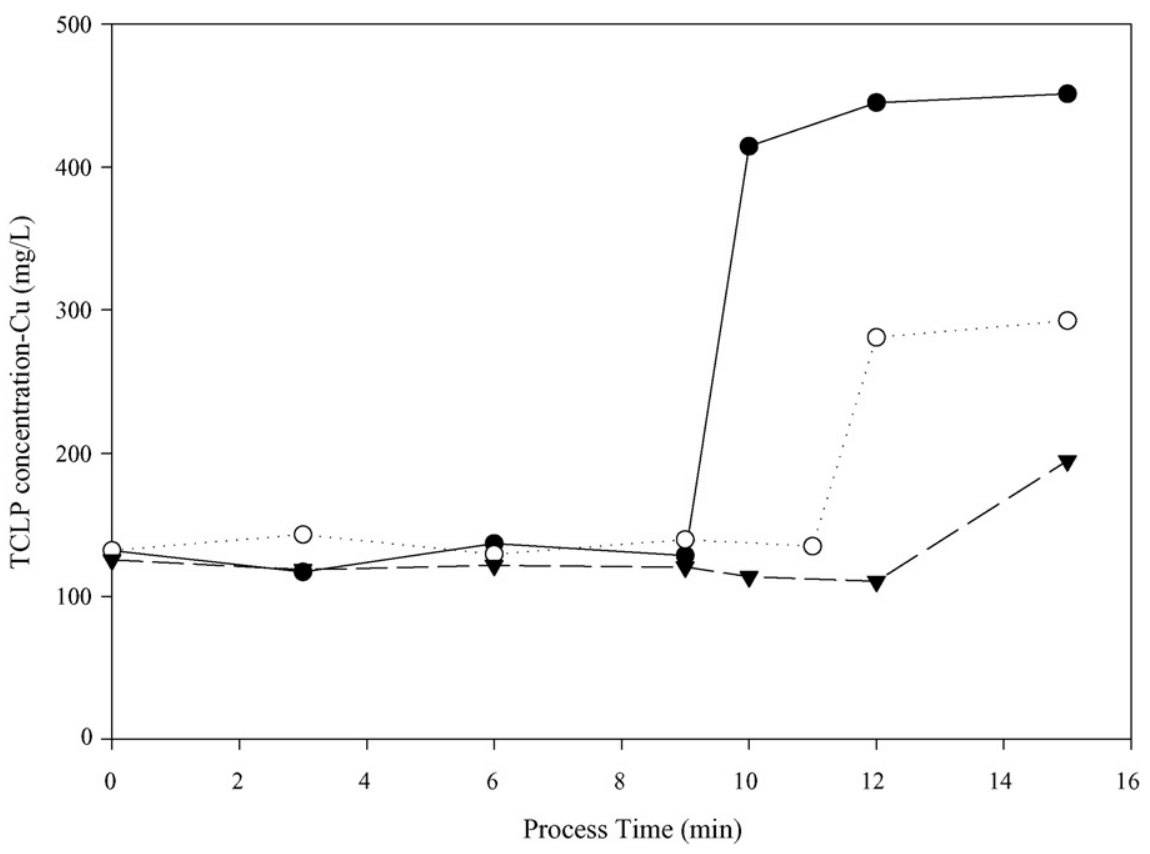

Fig. 3. The effect of atmosphere and cooling gas without additive: $(\bullet)$ air/air, $(\bigcirc) \mathrm{N}_{2} /$ air, and $(\boldsymbol{\nabla}) \mathrm{N}_{2} / \mathrm{N}_{2}$.

smoldering. Additive/RS ratios of more than $0.58 / 40$ (g/g) minimized the effect of reaction atmosphere and cooling gas.

\subsection{Effect of organic substance}

During the process of microwave treatment, the organic substance played an important role in the stabilization of heavy metal sludge. In the preliminary study, similar experiments to Case IV in Table 3 were also performed. However, the results indicated that at the existence of aluminum powder whether the sludge smoldered or not, the leaching concentration of copper ions would still be affected (from 3.6 to $39 \mathrm{mg} / \mathrm{L}$ ). Concentration of 3.6 and $39 \mathrm{mg} / \mathrm{L}$ represented the smoldering case and the non-smoldering case, respectively. As indicated in Section 3.2, it was supposed that the smoldering of sludge and destruction

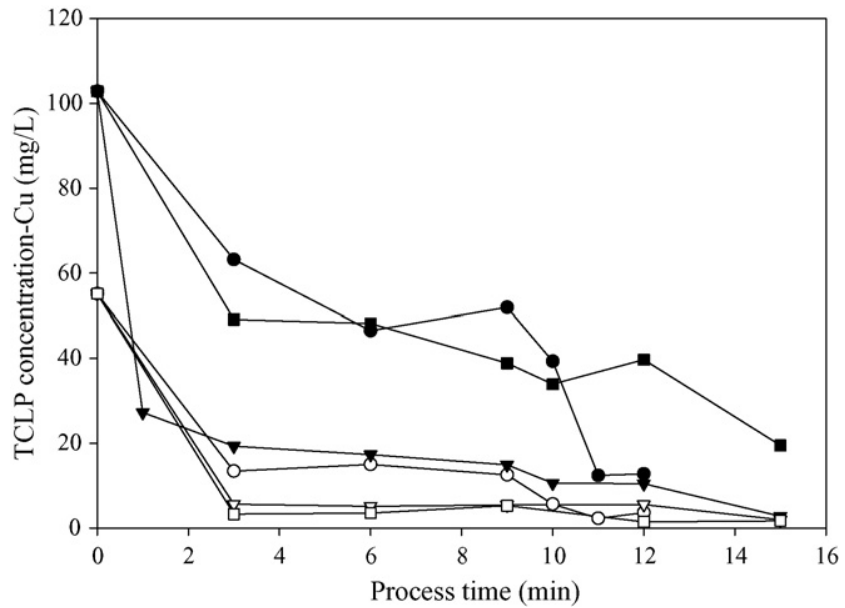

Fig. 4. The effect of atmosphere and cooling gas with additives. Addition of $0.58 \mathrm{~g} \mathrm{Al}$ powder with $(\bigcirc)$ Air/Air, $(\nabla) \mathrm{N}_{2} /$ Air, and $(\square) \mathrm{N}_{2} / \mathrm{N}_{2}$. Addition of $0.39 \mathrm{~g}$ Al powder with $(\bullet)$ Air/Air, $(\boldsymbol{\nabla}) \mathrm{N}_{2} /$ Air and $(\boldsymbol{\square}) \mathrm{N}_{2} / \mathrm{N}_{2}$. of organics would release the copper ions chelated by organics which would offer a positive opportunity for the collision between copper ions and aluminum powder.

Fig. 5 illustrates the two-stage stabilization with process time. The organic in the sludge was destroyed with a sludge mass loss of almost $25 \mathrm{wt} . \%$ during the first stage of processing. The second stage of processing stabilized the heavy metal sludge efficiently with little variation in the stabilizing curve and a temperature rose to only $200{ }^{\circ} \mathrm{C}$ even at a process time of $15 \mathrm{~min}$. These results imply that the organic is a good microwave adsorbent and its presence is advantageous in controlling temperature in the absence of oxygen. A similar result was found for the pyrolysis of sewage sludge [4]. Fig. 5 shows decreased for $\mathrm{Cu}$ leaching and increased $\mathrm{Fe}$ and $\mathrm{Al}$ leaching. The following two hypotheses may explain this behavior for stabilization by microwave heating. Hypothesis I: (1) $\mathrm{Al}^{0}$ reduces $\mathrm{Fe}^{3+}$ forming

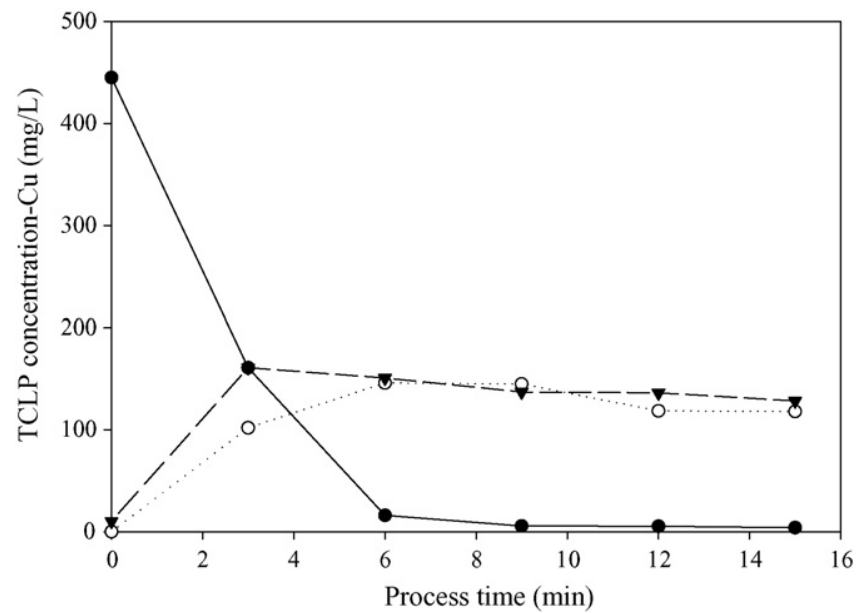

Fig. 5. Stabilizing curve of two-stage experiment: $(\bullet) \mathrm{Cu},(\bigcirc) \mathrm{Fe}$, and $(\mathbf{v}) \mathrm{Al}$. 


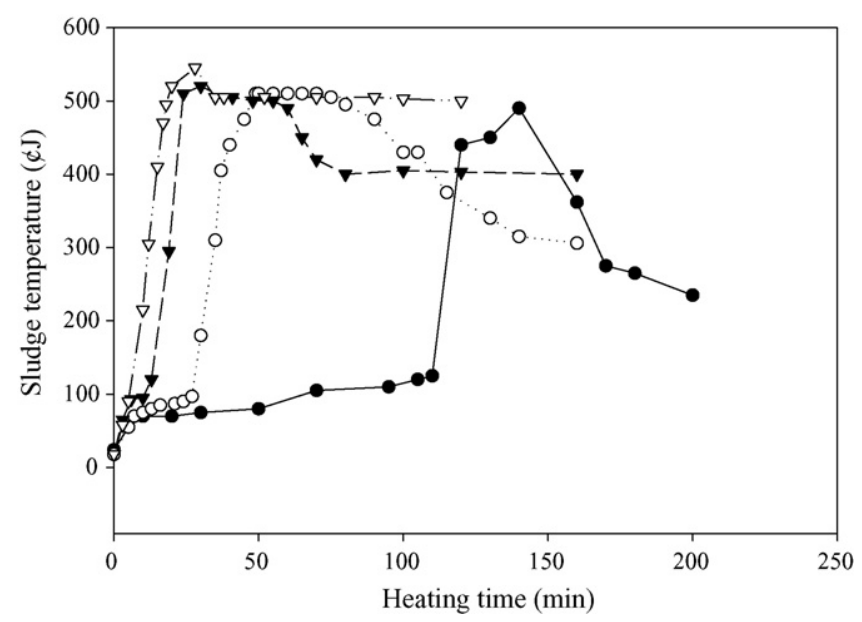

Fig. 6. Temperature variation of the heavy metal sludge without additive at conventional oven $(\bullet) 200^{\circ} \mathrm{C},(\bigcirc) 300^{\circ} \mathrm{C},(\boldsymbol{\nabla}) 400^{\circ} \mathrm{C}$, and $(\square) 500^{\circ} \mathrm{C}$.

$\mathrm{Al}^{3+}$ and $\mathrm{Fe}^{2+}$ or $\mathrm{Fe}^{0}$. (2) $\mathrm{Fe}^{2+}$ or $\mathrm{Fe}^{0}$ reduces $\mathrm{Cu}^{2+}$ forming $\mathrm{Cu}^{0}$ and $\mathrm{Fe}^{2+}$, contributing to the stabilization of $\mathrm{Cu}$ and the leaching of Fe. Hypothesis $\mathrm{II}^{\mathrm{Al}} \mathrm{Al}^{0}$ reduces $\mathrm{Fe}^{3+}$ and $\mathrm{Cu}^{2+}$ simultaneously forming $\mathrm{Fe}^{2+}$ and $\mathrm{Cu}^{0}$. The amorphous nature of the heavy metal sludge prevented detection of the compounds formed. Analytical identification of the chemical species is needed to better understand the chemical reactions occurring during microwave heating of the heavy metal sludge mixed with aluminum metal powder.

\subsection{Effect of temperature}

Samples of $50 \mathrm{wt} . \%$ sludge solids, $50 \mathrm{wt} . \%$ moisture, and no aluminum additive were placed in a conventional ovens held at a constant temperature ranging from 200 to $500{ }^{\circ} \mathrm{C}$ for $6 \mathrm{~h}$ and the sludge temperatures were monitored with time to study the effect of temperature. Fig. 6 illustrates the temperature of the heavy metal sludge with time at different conventional oven temperatures. The temperature curves show that the sludge temperature rose up to $500^{\circ} \mathrm{C}$, even with the oven temperature at $200^{\circ} \mathrm{C}$. Exothermic oxidation of the sludge organic accounts for the temperatures exceeding those of the oven. The sludge temperatures eventually declined to the oven temperatures in all the tests. Fig. 7 illustrates the resulting TCLP copper leaching concentration plotted against the oven temperatures, with and without the aluminum metal additive. The temperature curves including the aluminum metal powder additive (not displayed in Fig. 6) were no different than those without the additive. The results indicate that effective stabilization of the heavy metal sludge with the additive occurred at oven temperatures of $200^{\circ} \mathrm{C}$ and above. The TCLP copper leaching concentration maximized at $400.2 \mathrm{mg} / \mathrm{L}$ for the sludge without additive held at $300{ }^{\circ} \mathrm{C}$ and declined with oven temperature to $28.1 \mathrm{mg} / \mathrm{L}$ at $800^{\circ} \mathrm{C}$. Without additive, the leaching copper concentration declined gradually as the oven temperature increased above $400^{\circ} \mathrm{C}$. Just as with the microwave oven, the conventional oven effectively stabilized the sludge at 200 or above, when the aluminum metal powder addi-

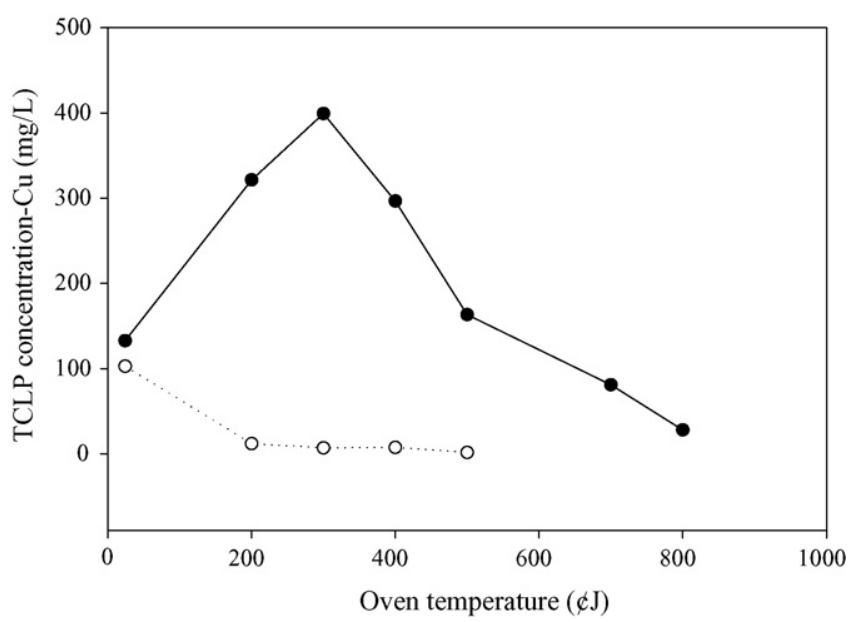

Fig. 7. TCLP concentration of copper ions from heating in the conventional oven $(\bigcirc)$ without additive $(\bigcirc)$ with additive.

tive was used. Higher temperatures do appear to stabilize the copper, even without additives. Extrapolating the plot in Fig. 7, a temperature of $850^{\circ} \mathrm{C}$ must be used without the additive to meet the Taiwan criterion of $15 \mathrm{mg} / \mathrm{L}$. This temperature can be achieved with either conventional or microwave heaters. Clearly, the aluminum metal powder allowed more effective stabilization of the heavy metal sludge at lower temperatures.

\section{Conclusion}

The study of stabilization of a heavy metal sludge generated by printed circuit board plants enhanced by microwave radiation led to the following conclusions:

1. The major elements of the raw heavy metal sludge are $\mathrm{Si}, \mathrm{Ca}$, $\mathrm{Fe}, \mathrm{Cu}$, and $\mathrm{Al}$ in decreasing sequence.

2. Microwave heating experienced no significant mass losses during treatment.

3. Adding aluminum metal powder made the thermal copper stabilization much more efficient and effective.

4. Increasing the microwave power and process time also improved copper stabilization. The reaction between copper ions and aluminum metal is a solid phase reaction, because the moisture vaporizes before the higher temperatures are achieved.

5. An inert reaction atmosphere $\left(\mathrm{N}_{2}\right)$ during heating and oxidizing atmosphere (air) for cooling gave better performance.

6. The organic content in the heavy metal sludge affected the stabilizing curve, whether or not the organic was destroyed (smoldered) during treatment.

7. Exothermic oxidation of the organic results in a sludge temperature higher than the temperature in a conventional oven

8. The reducing ability of aluminum metal and higher temperatures stabilized the copper in the heavy metal sludge heated by microwave radiation or in a conventional oven. 


\section{Acknowledgement}

The authors convey their gratitude to the Ministry of Economic Affairs of the Republic of China (Contract No.: 93-EC17-A-10-S1-0007) for financial supports.

\section{References}

[1] N.L. Nemerow, Industrial Water Pollution: Origins, Characteristics and Treatment, Addison-Weisly, New York, 1978.

[2] A. Loupy, Microwaves in Organic Synthesis, Wiley-VCH Verlag GmbH \& Co. KGaA, Weinheim, 2002.

[3] E.T. Thostenson, T.W. Chou, Microwave processing: fundamentals and application, Composite, Part A: Appl. Sci. Manuf. 30 (1999) 1055-1071.

[4] J.A. Menendez, M. Inguanzo, J.J. Pis, Microwave-induced pyrolysis of sewage sludge, Water Res. 36 (2002) 3261-3264.

[5] A.A.A. Samra, J.S. Morris, S.R. Koirtyohann, Wet ashing of some biological samples in a microwave oven, Anal. Chem. 47 (8) (1975) 1475-1477.

[6] K.J. Lamble, S.J. Hill, Critical review-microwave digestion procedures for environmental materials, Analyst 123 (1998) 103R-133R.

[7] B. Perez-Cid, I. Lavilla, C. Bendicho, Application of microwave extraction for partitioning of heavy metals in sewage sludge, Anal. Chim. Acta 378 (1999) 201-210.

[8] C.Y. Kuo, C.H. Wu, S.L. Lo, Removal of copper from industrial sludge by traditional and microwave acid extraction, J. Hazard. Mater. B 120 (2005) 249-256.

[9] Y.K. Huang, J.S. Chang, Y.U. Kwon, S.E. Park, Microwave synthesis of cubic mesoporous silica SBA-16, Micropor. Mesopor. Mater. 68 (2004) $21-27$.
[10] I. Kubrakova, Microwave-assisted sample preparation and preconcentration for ETAAS, Spectrochim. Acta, Part B: Atom. Spectrosc. 52 (1997) 1469-1481.

[11] S.W. Kingman, N.A. Rowson, Microwave treatment of minerals—a review, Miner. Eng. 11 (11) (1998) 1081-1087.

[12] S.K. Vanttan, B.A. Docols, D.B. Green, Microwave-assisted synthesis of group $6(\mathrm{Cr}, \mathrm{Mo}, \mathrm{W})$ zerovalent organometallic carbonyl compounds, Organometallics 19 (2000) 2397-2399.

[13] S.E. Park, D.S. Kim, J.S. Chang, W.Y. Kim, Synthesis of MCM-41 using microwave heating with ethylene glycol, Catal. Today 44 (1998) 301308.

[14] H.S. Tai, C.J.G. Jou, Immobilization of chromium-contaminated soil by means of microwave energy, J. Hazard. Mater. B 65 (1995) 267275.

[15] C.L. Chen, S.L. Lo, W.H. Kuan, C.H. Hsieh, Stabilization of Cu(II) in acid extracted industrial sludge using a microwave process, J. Hazard. Mater. B 123 (2005) 256-261.

[16] C.J.G. Jou, An efficient technology to treat heavy metal-lead-contaminated soil by microwave radiation, J. Environ. Manage. 78 (2006) 1-4.

[17] Q. Gan, A case study of microwave processing of metal hydroxide sediment sludge from printed circuit board manufacturing wash water, Waste Manage. 20 (2000) 695-701.

[18] E. Sedhom, L. Dauerman, N. Ibrahim, G. Windgasse, Microwave treatment of hazardous wastes: "fixation" of chromium in soil, J. Microwave Power Electromagn. Energy 27 (2) (1992) 81-86.

[19] V. Sandroni, C.M.M. Smith, A. Donovan, Microwave digestion of sediment, soil and urban particulate matter for trace metal analysis, Talanta 60 (2003) 715-723. 